\title{
Özel Eğitimde Teknoloji Kullanımına İliş̧kin Araştırmalarda Güncel Eğilimler: Türkiye'de Lisansüstü Tezler Üzerine Bir İnceleme
}

\author{
Current Trends in Research on Technology Use in Special \\ Education: A Review on Postgraduate Theses in Turkey
}

\begin{tabular}{|c|c|}
\hline & Cansu ÇAKA ${ }^{1}$ \\
\hline 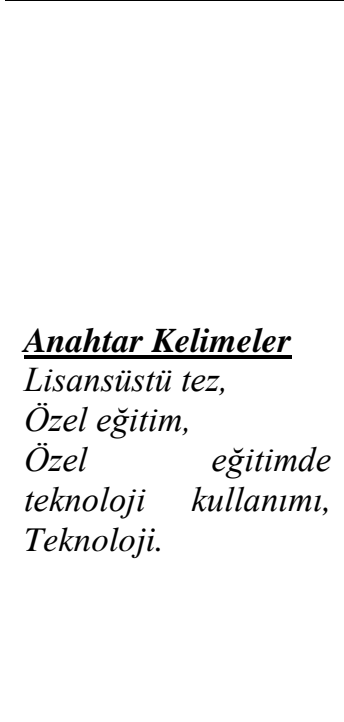 & 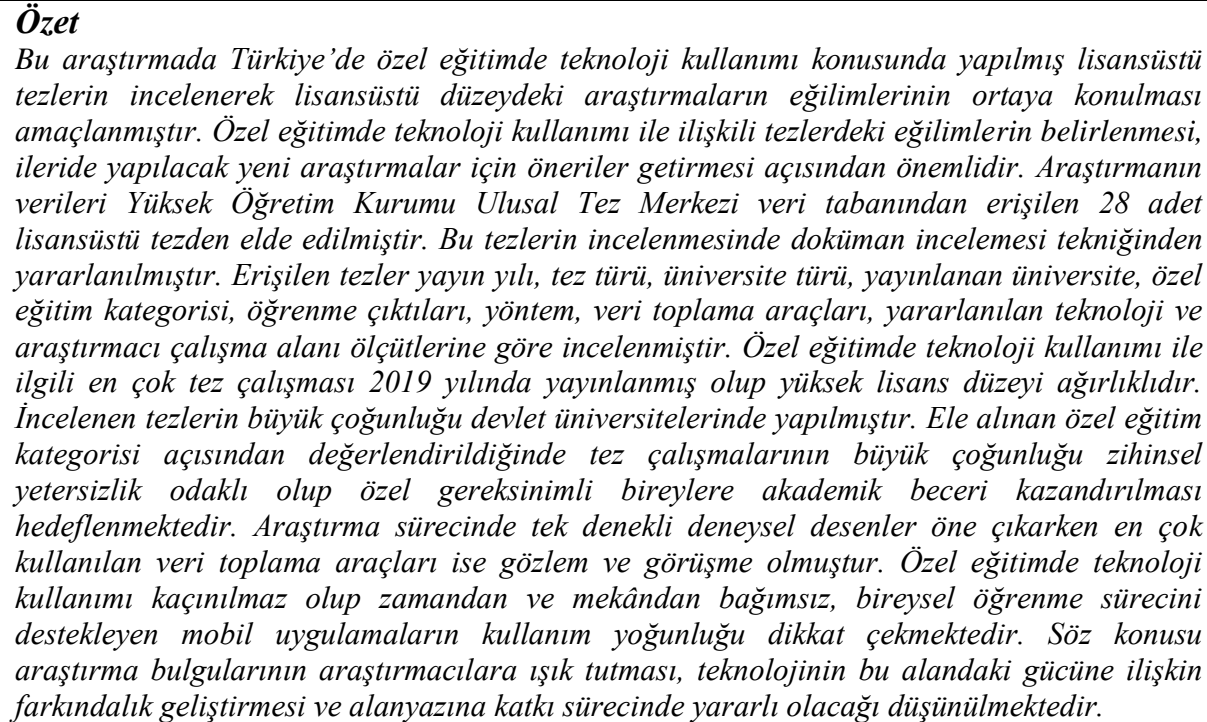 \\
\hline
\end{tabular}

\section{Abstract}

This research has been made about the use of technology in examining the special education graduate thesis research in Turkey was aimed to determine the trend. Determining the trends in the theses related to the use of technology in special education is important in terms of providing suggestions for future research. The research data were obtained from 28 postgraduate theses accessed from the database of the National Thesis Center of the Council of Higher Education. Document analysis technique was used to examine these theses. The

$\underline{\text { Key Word }}$

Postgraduate thesis, Special education, Use of technology in special education, Technology. accessed theses were analyzed according to the publication year, thesis type, university type, published university, special education category, learning outcomes, method, data collection tools, technology used, and researcher field of study. The most thesis on the use of technology in special education was published in 2019, and it is mostly master level. Most of the examined theses were made in state universities. When evaluated in terms of the special education category under consideration, most of the theses are focused on mental disability and it is aimed to gain academic skills to individuals with special needs. While single-subject experimental designs came to the fore in the research process, the most used data collection tools were observation and interview. The use of technology in special education is inevitable, and the intensity of use of mobile applications that support the individual learning process, independent of time and space, draws attention. It is thought that the research findings in question will be useful in the process of shedding light on researchers, raising awareness of the power of technology in this field and contributing to the literature. $\begin{array}{ll}\begin{array}{l}\text { Atıf için: } \\ \text { For Citation }\end{array} & \text { Çaka, C. (2020). Özel eğitimde teknoloji kullanımına ilişkin araştırmalarda güncel eğilimler: } \\ & \text { türiye'de lisansüstü tezler üzerine bir inceleme. Muğla Sitkı Koçman Üniversitesi Eğitim } \\ & \text { Fakültesi [MSKU Journal of Education], 7(2), 133-143. DOI: 10.21666/muefd.749292 }\end{array}$ Received: 08.06.2020 Accepted: 27.09.2020 $\quad$ Published: 01.11.2020

\footnotetext{
${ }^{1}$ Muğla Sıtkı Koçman Üniversitesi Eğitim Fakültesi, cansucaka@mu.edu.tr, ORCID: 0000-0001-9110-2544
} 
İnsanlar birçok açıdan birbirlerinden farklı olup bu farklılıkların sebepleri, birey ve topluma muhtemel etkileri, her dönem ilgi çeken konuların başında gelmiştir (Kuzgun ve Deryakulu, 2006). Bedensel, zihinsel, psikolojik ya da davranışsal farklılıklar; bu bireylerin diğer insanlardan farklı olarak algılanmasına yol açmakta ve bu farklılıklar da bireysel farklılık olarak adlandırılmaktadır. $\mathrm{Bu}$ farklılıklar kimi zaman normal kabul edilmiş ve kişinin toplum tarafindan kabulü sağlanmışken kimi zaman ise kişinin toplumun bir üyesi olarak kabul edilmesi sürecini zorlaştırmıştır.

Özel gereksinimli bireylere yönelik olarak alanyazında farklı kavramlar kullanılabilmekle birlikte; en sık kullanılan kavram engel kavramıdır. Engel durumu; kişinin bir zedelenme durumuyla karşı karşıya kalması ve bu durumun sonucunda ortaya çıkan yetersizlik durumunun çevre ile etkileşime girmesi neticesinde oluşmaktadır (WHO [World Health Organization], 1980).

Özel gereksinimi olan bireyler temel olarak şu şekilde sinıflandırılmaktadır (Turnbull, Turnbull, Wehmeyer ve Shogren, 2016);

$>$ Zihinsel yetersizlik

$>$ Öğrenme güçlüğü

$>$ Duygusal ve davranış bozuklukları

$>$ Dikkat eksikliği ve hiperaktivite bozukluğu

$>$ Otizm spektrum bozukluğu

$>$ Dil ve konuşma bozukluğu

$>$ İşitme yetersizliği

$>$ Görme yetersizliği

$>$ İleri derecede ve çoklu yetersizlik

$>$ Fiziksel yetersizlik

$>$ Travmatik beyin yaralanmas 1

$>$ Üstün zekalilar ve üstün yetenekliler

MEB [Millî Eğitim Bakanlığı] (2006) tarafindan, çeşitli nedenlerle bireysel ve gelişim özellikleri ile eğitim yeterlilikleri açısından akranlarından beklenen düzeyden anlamlı farklılık gösteren bireylerin özel eğitim kapsamına alınması gerektiği ifade edilmektedir. Özel eğitim ve ilişkili kavramlar 573 Sayılı Özel Eğitim Hakkında Kanun Hükmünde Kararname'de (573-KHK) tanımlanarak 6/6/1997 tarihinde kabul edilmiştir. Bu çerçevede özel eğitim gereksinimi olan birey, birtakım nedenlerden kaynaklı, bireysel özellikleri ve eğitim yeterlilikleri bakımından akranlarından beklenilen düzeyden anlamlı düzeyde farklılık gösteren birey olarak tanımlanmıştır.

Özel Eğitim Hakkında Kanun Hükmünde Kararname (573-KHK)'de (1997) özel eğitim, özel eğitim gerektiren bireylerin eğitim gereksinimlerini karşılamak için özel olarak yetiştirilmiş personel, geliştirilmiş eğitim programları ve yöntemleri ile düzenlenmiş uygun öğrenme ortamlarında sürdürülen eğitim olarak tanımlanmaktadır.

Büyük insan toplulukları, aşırı hareket, dinamizm, hızlı değişim, bilimsellik ve gelişmiş teknoloji, içinde bulunduğumuz çağı temsil eden temel niteliklerdir. Teknoloji; endüstri, ticaret, tarım başta olmak üzere tüm hizmet sektörlerinde göstermiş olduğu olumlu etkileri, eğitim alanına da yansitabilecek potansiyele sahiptir. Hızla artan öğrenci kitlelerini geleneksel eğitim sisteminin kalıpları içinde barındırmak mümkün olmayıp eğitim ve teknoloji, insan yaşamının daha etkin duruma getirilmesi sürecinde önemli gücü olan temel ögelerdir (Alkan, 2005). Bilim ve teknolojide meydana gelen gelişmeler eğitim alanında da bir dönüşüm sürecini beraberinde getirmektedir. Eğitim hizmetleri, toplumların gelişmesinde ve kalkınmasında daha da önem kazanmaktadır. Bu çerçevede bilgi toplumunda her zamankinden daha fazla bilimsel ve teknolojik desteğe gereksinim duyulmaktadır. Bilim ve teknolojide meydana gelen hızlı gelişmeler ve toplumsal gereksinimlerdeki değişimler eğitime yeni görev ve sorumluluklar yüklemektedir (Alkan, 2005). Metin, ses, video, kullanıcının bireysel gereksinimlerine uygun ve dönüt veren yazılımlarla eğitim ortamına dahil olan teknoloji; günümüzde artık kullanıcıların gereksinim duydukları bilgilere mobil araçlarla eriştikleri, görsel, işitsel ve duyuşsal özelliklerini hissedebildikleri sanal ortamlara kadar gelişmiştir. Normal gelişim gösteren bireylerin eğitiminde olduğu gibi özel eğitime gereksinim duyan bireylerin eğitiminde de teknolojinin bu gücünden yararlanılmaktadır (Ray ve Atwill, 2004; Sherman ve De La Paz, 2018). Tüm bireylerin eğitiminde olduğu gibi özel eğitime gereksinim duyan bireylerin eğitiminde de onların ileride bağımsız yaşam sürdürebilmeleri, kendi kendilerine yetecek duruma gelebilmeleri ve toplumla bütünleşebilmeleri hedeflenmektedir. Özel gereksinimi olan bireyler de akranlarının sahip olduğu temel haklara sahiptir. Özel eğitime gereksinim duyan bireyler için firsat 
eşitliğinin sağlanması ve bu öğrencilerin bireysel gereksinimlerine hitap edecek şekilde öğrenme ortamlarının oluşturulabilmesi sürecinde öğretim teknolojileri etkin bir şekilde işe koşulabilmektedir. Teknoloji, özel gereksinimli bireylerin öğrenme kapasitesini arttırma, iletişimi kolaylaştırma, bağımsızlıklarını arttırma sürecinde önemli bir role sahiptir (Ayres ve Langone, 2005; Hammond, Whatley, Ayres ve Gast, 2010; Mechling ve Gustafson, 2008; Sula ve Spaho, 2014; Westling ve Fox, 2009; Zisimopoulos, Sigafoos ve Koutromanos, 2011).

Bilgi ve iletişim teknolojilerinde meydana gelen gelişmelerin yansımaları, genel eğitim yaklaşımlarının ve eğitimde kullanılan teknolojilerin de gelişimini sağlamış ve özürlülük kavramı yerini yetersizlik kavramına bırakmıştır. Teknolojinin eğitime yansımaları şu şekilde ele alınmaktadır (Blackhurst, 2005),

$>$ Öğretimin teknolojisi (öğretim tasarımı)

$>$ Öğretim teknolojileri (video gibi araç gereçler)

$>$ Destekleyici teknolojiler (engelli bireylere yardımcı araçlar)

$>$ Tibbi teknolojiler (hastaları rahatlatmaya yönelik teknolojiler)

$>$ Teknoloji üretim araçları (bilgisayar yazılım ve donanımı)

$>$ Bilgi teknolojisi (bilgi kaynaklarına erişim)

Yetersizlik kaynaklı engeller; özel eğitim yaklaşımlarındaki, eğitim teknolojisindeki ve destekleyici gereçlerdeki gelişmeler aracılığıla ya tamamen ortadan kaldırılabilmekte ya da en aza indirgenebilmektedir (Girgin, 2010). Özel eğitimde teknolojinin gücü yadsınamaz bir gerçektir. Dolayısıyla özel eğitimde teknoloji kullanımı, son dönemlerde ilgi gören bir araştırma alanıdır. Ancak alanyazın incelendiğinde özel eğitimde teknoloji kullanımı ile ilişkili lisansüstü düzeyde araştırma eğilimlerini ortaya koyan bir çalışmaya rastlanılmamıştır. Bu durum, özel eğitimde teknoloji kullanımı ile ilişkili tez çalışmalarındaki eğilimlerin belirlenmesi ve ileride yapılacak yeni araştırmalar için öneri getirmesi açısından gerekli ve önemlidir.

$\mathrm{Bu}$ araştırmada Türkiye'de özel eğitimde teknoloji kullanımı konusunda yapılmış lisansüstü tezlerin incelenerek lisansüstü düzeydeki araştırmaların eğilimlerinin ortaya konulması amaçlanmıştır. $\mathrm{Bu}$ amaç doğrultusunda Türkiye'de günümüze kadar özel eğitimde teknoloji kullanımına ilişkin yürütülen lisansüstü tezlerle ilgili şu sorulara yanıt aranmıştır:

Özel eğitimde teknoloji kullanımı ile ilgili lisansüstü tezlerin

$>$ Yayın yılına

$>$ Tez türüne

$>$ Yayınladığı üniversite türüne

$>$ Yayınlandığı üniversiteye

$>$ Ele alınan özel eğitim kategorisine

$>$ Elde edilen öğrenme çıktılarına

$>$ Kullanilan yönteme

$>$ Kullanılan veri toplama araçlarına

$>$ Yararlanılan teknolojilere

> Araştırmacı çalışma alanına göre dağılımı nasıldır?

\section{Yöntem}

\section{Araştırma Deseni}

Araştırma nitel araştırma desenlerinden durum çalışmasına göre planlanmıştır. Durum çalışması, bir ya da daha fazla olayın, ortamın, programın, sosyal grubun veya diğer birbirine bağlı sistemlerin derinlemesine incelendiği bir yöntem olarak ifade edilmektedir (McMillan, 2000).

\section{Araştırmanın Örneklemi}

Araştırmanın örneklemini, 2020 yılına kadar yayınlanan ve YÖK [Yükseköğretim Kurulu] Ulusal Tez Merkezi veri tabanına kayıtlı olan özel eğitimde teknoloji kullanımı ile ilgili yapılan lisansüstü tezler oluşturmaktadır. Araştırmanın örnekleminin belirlenmesinde araştırmaya konu olan örnekleme belirli bir ölçüt getirilmesiyle oluşan amaçlı örnekleme yöntemlerinden ölçüt örnekleme kullanılmıştır (Büyüköztürk vd., 2013). 


\section{Verilerin Toplanması}

Araştırmada veriler doküman incelemesi yoluyla toplanmıştır. Nitel bir araştırmada doğrudan görüşme veya gözlemin olanaklı olmadığı durumlarda doküman incelemesi, araştırılmak istenen olgu hakkında gözlem ve görüşme yapmaya gerek olmaksızın yazılı materyalleri analiz etmede kullanılan bir yöntemdir (Yıldırım ve Şimşek, 2011). Araştırma verilerinin toplanması sürecinde şu aşamalar izlenmiştir;

> Dokümanlara Ulaşma: Bu aşamada özel eğitimde teknoloji kullanımı konusunda yazılan yüksek lisans ve doktora tezleri "özel eğitim", "teknoloji” ve "yardımcı teknoloji” anahtar kelimeleriyle YÖK Ulusal Tez Merkezi veri tabanı üzerinden taranmıştır.

> Orijinalliği Kontrol Etme: YÖK Ulusal Tez Merkezi veri tabanından erişilen lisansüstü tezlerin orijinalliği bu yolla kontrol edilmiştir.

$>$ Dokümanları Anlama: Araştırma dokümanları tek tek araştırma soruları ile ilişkilendirilmiştir.

$>$ Veriden Örneklem Seçme: Bu araştırmada analiz yapılan dokümanlarda örnekleme yoluna gidilmeyip araştırma amacı doğrultusunda elde edilen tüm dokümanlar tasnif edilmiştir.

> Kategorilerin Geliştirilmesi: $\mathrm{Bu}$ aşamada araştırmanın amacından yola çıkılarak ilgili kategoriler geliştirilmiştir.

\section{Veri Analizi}

Araştırma kapsamında elde edilen veriler betimsel analiz yöntemiyle analiz edilmiştir. Betimsel analiz, verilerin özgün formuna bağlı kalarak ve doğrudan alıntılar yaparak önceden belirlenmiş bir çerçeve dahilinde nitel verilerin işlenmesidir. $\mathrm{Bu}$ analiz yönteminde temel amaç, elde edilen bulguları okuyucuya 'özetlenmiş ve yorumlanmış' bir şekilde aktarmaktır (Yıldırım ve Şimşek, 2011). Her lisansüstü tez yayın yılı, tez türü, yayınlandığg üniversite türü, yayınlandığı üniversite, ele alınan özel eğitim kategorisi, kullanılan yöntem, kullanılan veri toplama araçları, yararlanılan teknoloji, araştırmacı çalışma alanı ve elde edilen öğrenme çıktıları gibi kategorilerde ayrı ayrı incelenmiştir. Araştırma kapsamında 28 tez incelenmiş olup bulgular tablolarla gösterilmiştir.

\section{Bulgular}

\section{Tezlerin Yıllara ve Türlerine İlişkin Bulgular}

İncelenen tezlerin yayınlanma yıllarına ve türlerine ilişkin dağılım Tablo 1'de sunulmuştur.

Tablo 1

Özel Ĕgitimde Teknoloji Kullanımı ile İlgili Tezlerin Yıllara ve Türe Göre Dağılımı

\begin{tabular}{|c|c|c|c|c|c|c|}
\hline \multicolumn{7}{|c|}{ Tez Türü } \\
\hline \multicolumn{2}{|c|}{ Yillar } & \multicolumn{2}{|c|}{ Yüksek Lisans } & \multirow{2}{*}{$\begin{array}{c}\text { Doktora } \\
\%\end{array}$} & \multicolumn{2}{|c|}{ Toplam } \\
\hline & $f$ & $\%$ & $f$ & & $f$ & $\%$ \\
\hline 2006 & 1 & 6,2 & - & - & 1 & 3,6 \\
\hline 2007 & - & - & 1 & 8,3 & 1 & 3,6 \\
\hline 2008 & 1 & 6,2 & - & - & 1 & 3,6 \\
\hline 2009 & 1 & 6,2 & - & - & 1 & 3,6 \\
\hline 2010 & - & - & - & - & - & - \\
\hline 2011 & 1 & 6,2 & 1 & 8,3 & 2 & 7,2 \\
\hline 2012 & - & - & - & - & - & - \\
\hline 2013 & - & - & 1 & 8,3 & 1 & 3,6 \\
\hline 2014 & 1 & 6,2 & 1 & 8,3 & 2 & 7,2 \\
\hline 2015 & 2 & 12,4 & 2 & 16,6 & 4 & 14,4 \\
\hline 2016 & 4 & 24,8 & - & - & 4 & 14,4 \\
\hline 2017 & 2 & 12,4 & 1 & 8,3 & 3 & 10,8 \\
\hline 2018 & 1 & 6,2 & 2 & 16,6 & 3 & 10,8 \\
\hline 2019 & 2 & 12,4 & 3 & 24,9 & 5 & 18 \\
\hline Toplam & 16 & 57 & 12 & 43 & 28 & 100 \\
\hline
\end{tabular}


Tablo 1'e göre en fazla yüksek lisans tezinin yapıldığı yıl $2016(f=4)$ iken en fazla doktora tezinin yapıldığı yıl $2019(f=3)$ olmuştur. Özel eğitimde teknoloji kullanımı ile ilgili lisansüstü tezler genel olarak incelendiğinde en çok tez üretilen y1l 2019 yılı olurken $(f=5) ; 2010$ ve 2012 y1llarında bu konuya ilişkin ne yüksek lisans ne de doktora tezi yayınlanmamıştır.

\section{Tezlerin Yayınlandığı Üniversite Türüne İlişskin Bulgular}

İncelenen tezlerin yayınlandığı üniversite türüne ilişkin dağılım Tablo 2'de sunulmuştur.

Tablo 2

Özel Ĕgitimde Teknoloji Kullanımı ile İlgili Tezlerin Yayınlandĭ̆ı Üniversite Türüne Göre Dă̆ılımı

\begin{tabular}{ccccccc}
\hline \multicolumn{7}{c}{ Tez Türü } \\
\hline Üniversite Türü & Yüksek Lisans & \multicolumn{1}{c}{ Doktora } & Toplam \\
\cline { 2 - 7 } & $\boldsymbol{f}$ & $\boldsymbol{\%}$ & $\boldsymbol{f}$ & $\boldsymbol{\%}$ & $\boldsymbol{f}$ & $\boldsymbol{\%}$ \\
\hline Devlet & 11 & 69 & 12 & 100 & 23 & 82 \\
Vakıf & 5 & 31 & - & - & 5 & 18 \\
\hline
\end{tabular}

Tablo 2'ye göre özel eğitimde teknoloji kullanımı ile ilgili tezlerin büyük çoğunluğu devlet üniversitelerinde yapılmış olup $(f=23)$, yüksek lisans ve doktora tezleri hemen hemen aynı sayıdadır. Diğer yandan vakıf üniversitelerinde yapılan tezlerin tamamının yüksek lisans düzeyinde olması dikkat çekmektedir.

\section{Tezlerin Yayınlandığı Üniversitelere İlişkin Bulgular}

İncelenen tezlerin yayınlandığı üniversitelere ilişkin dağılım Tablo 3 ’te sunulmuştur.

Tablo 3

Özel Eğitimde Teknoloji Kullanımı ile İlgili Tezlerin Yayınlandı̆̆ Üniversitelere Göre Dağılımı

\begin{tabular}{lc}
\multicolumn{1}{c}{ Üniversite } & $f$ \\
\hline Abant İzzet Baysal Üniversitesi & 2 \\
Anadolu Üniversitesi & 7 \\
Ankara Üniversitesi & 1 \\
Atatürk Üniversitesi & 1 \\
Bahçeşehir Üniversitesi & 2 \\
Beykent Üniversitesi & 1 \\
Gazi Üniversitesi & 2 \\
Hacettepe Üniversitesi & 1 \\
İstanbul Aydın Üniversitesi & 2 \\
Karadeniz Teknik Üniversitesi & 1 \\
Orta Doğu Teknik Üniversitesi & 4 \\
Sakarya Üniversitesi & 1 \\
Trakya Üniversitesi & 2 \\
Uludağ Üniversitesi & 1 \\
\hline \multicolumn{2}{c}{ Toplam } \\
\hline
\end{tabular}

Tablo 3'e göre özel eğitimde teknoloji kullanımı ile ilgili en çok tez çalışması Anadolu Üniversitesi'nde yürütülmüş $(f=7)$ olup bunu Orta Doğu Teknik Üniversitesi takip etmektedir $(f=4)$.

\section{Tezlerde Ele Alınan Özel Eğitim Kategorisine İlişkin Bulgular}

İncelenen tezlerin ele aldığı özel eğitim kategorisine ilişkin dağılım Tablo 4'te sunulmuştur. 
Tablo 4

Özel Eğitimde Teknoloji Kullanımı İle İlgili Tezlerin Ele Alınan Özel Eğitim Kategorisine Göre

Dağılımı

\begin{tabular}{lc}
\multicolumn{1}{c}{ Ele Alınan Özel Eğitim Kategorisi } & $\boldsymbol{f}$ \\
\hline Çoklu Yetersizlik & 3 \\
Dil ve İletişim Bozuklukları & 2 \\
Erken Çocukluk Özel Eğitimi & 1 \\
Görme Yetersizliği & 2 \\
İşitme Yetersizliği & 1 \\
Otizm Spektrum Bozukluğu & 5 \\
Öğrenme Güçlüğü & 3 \\
Zihinsel Yetersizlik & 11 \\
\hline
\end{tabular}

Tablo 4'e göre özel eğitimde teknoloji kullanımı ile ilgili tezler ele alınan özel eğitim kategorisi açısından değerlendirildiğinde tez çalışmalarının büyük çoğunluğu zihinsel yetersizlik kategorisi odaklı iken $(f=11)$, en az tez çalışması erken çocukluk eğitimi $(f=1)$ ve işitme yetersizliği $(f=1)$ kategorilerinde yürütülmüştür.

\section{Tezlerin Öğrenme Çıktılarına İlişskin Bulgular}

İncelenen tezlerin öğrenme çıtıllarına ilişkin dağılım Tablo 5 'te sunulmuştur.

Tablo 5

Özel Eğitimde Teknoloji Kullanımı ile İlgili Tezlerin Öğrenme Çıktılarına Göre Dă̆ıllımı

\begin{tabular}{ll}
\multicolumn{1}{c}{ Öğrenme Çıktıları } & $f$ \\
\hline Akademik Beceriler & 19 \\
Bağımsız Yaşam Becerileri & 2 \\
Bilişssel Beceriler & 2 \\
Gelişim İzleme ve Raporlama & 1 \\
Mesleki ve Günlük Yaşam Becerisi & 3 \\
Sosyal Etkileşim ve İletişim Becerileri & 5 \\
\hline
\end{tabular}

Tablo 5'e göre özel eğitimde teknoloji kullanımı ile ilgili tezlerde öğrenme çıktıları büyük ölçüde okuma, yazma, kavram öğrenme gibi akademik beceri odaklıdır $(f=19)$. Diğer yandan gelişim izleme ve raporlama $(f=1)$, bağımsız yaşam becerileri $(f=2)$ ve bilişsel beceriler $(f=2)$ odaklı tezler daha sınırlı kalmıştır.

\section{Tezlerde Kullanılan Yöntemlere İlişkin Bulgular}

İncelenen tezlerde kullanılan yöntemlere ilişsin dağılım Tablo 6' da sunulmuştur.

Tablo 6

Özel Ĕgitimde Teknoloji Kullanımı ile İlgili Tezlerin Kullanılan Yöntemlere Göre Dağılımı

\begin{tabular}{ll}
\hline \multicolumn{1}{c}{ Kullanılan Yöntem } & $\boldsymbol{f}$ \\
\hline Deneysel & 11 \\
Durum Çalışması & 7 \\
Eylem Araştırması & 2 \\
Tasarım Tabanlı & 8 \\
\hline
\end{tabular}

Tablo 6'ya göre özel eğitimde teknoloji kullanımı ile ilgili tezlerde en çok deneysel araştırmalar yürütülmüştür $(f=11)$. Deneysel araştırmalarda ise tek denekli deneysel desenler öne çıkmaktadır. Buna karşın en az tercih edilen yöntemin eylem araştırması olduğu görülmektedir $(f=2)$.

Tezlerde Kullanılan Veri Toplama Araçlarına İlişkin Bulgular

İncelenen tezlerde kullanılan veri toplama araçlarına ilişkin dağılım Tablo 7'de sunulmuştur. 
Tablo 7

Özel Eğitimde Teknoloji Kullanımı ile İlgili Tezlerin Kullanılan Veri Toplama Araçlarına Göre

Dağılımı

\begin{tabular}{lc}
\hline \multicolumn{1}{c}{ Kullanılan Veri Toplama Araçları } & $\boldsymbol{f}$ \\
\hline Anket & 3 \\
Gözlem & 19 \\
Günlük & 4 \\
Log verileri & 3 \\
Görüsme & 18 \\
Öğrenci dosyaları & 5 \\
\hline
\end{tabular}

Tablo 7'ye göre özel eğitimde teknoloji kullanımı temelli tez çalışmalarında araştırmacılar tarafından en çok kullanılan veri toplama araçları gözlem $(f=19)$ ve görüşme $(f=18)$ iken en az kullanılan veri toplama araçları ise anket $(f=3)$ ve log verileridir $(f=3)$.

\section{Tezlerde Kullanılan Yardımcı Teknolojilere İlişkin Bulgular}

İncelenen tezlerde kullanılan yardımcı teknolojilere ilişkin dağılım Tablo 8'de sunulmuştur.

Tablo 8

Özel Eğitimde Teknoloji Kullanımı İle İlgili Tezlerin Kullanılan Teknolojilere Göre Dă̆ıllımı

\begin{tabular}{ll}
\hline \multicolumn{1}{c}{ Kullanılan Teknoloji } & $f$ \\
\hline Çoklu Ortam & 3 \\
Eğitsel Oyun & 2 \\
Mobil Uygulamalar & 9 \\
Öğretim Yazılııı & 5 \\
Web Tabanlı Eğitim & 4 \\
Video & 2 \\
Arttırılmış Gerçeklik & 1 \\
EPDS & 1 \\
Yapay Zekâ & 1 \\
\hline
\end{tabular}

Tablo 8'e göre özel eğitimde teknoloji kullanımı ile ilgili tezlerde mobil uygulamaların kullanım yoğunluğu öne çıkmaktadır $(f=9)$. Diğer yandan teknolojik gelişmeler 1şığında özel eğitim alanında son yıllarda henüz çok sınırlı olmakla birlikte arttırılmış gerçeklik $(f=1)$, EPDS $(f=1)$ ve yapay zekâ $(f=1)$ gibi teknolojileri temel alan çalışmaların da yürütüldüğü görülmektedir.

\section{Tezleri Yürüten Araştırmacıların Çalışma Alanlarına İlişkin Bulgular}

İncelenen tezlerin araştırmacı çalışma alanlarına ilişkin dağılım Tablo 9'da sunulmuştur.

Tablo 9

Özel Eğitimde Teknoloji Kullanımı ile İlgili Tezlerin Araştırmacı Çalışma Alanlarına Göre Dağılımı

\begin{tabular}{lc}
\multicolumn{1}{c}{ Araştırmacı Alanı } & $f$ \\
\hline Bilgi Teknolojileri & 1 \\
Bilgisayar Mühendisliği & 2 \\
Bilgisayar ve Öğretim Teknolojileri Eğitimi & 11 \\
Eğitim Teknolojileri & 1 \\
Fen Bilgisi Eğitimi & 1 \\
Güzel Sanatlar Eğitimi & 1 \\
İletişim Sanatları ve Tasarım & 1 \\
Özel Eğitim & 8 \\
Psikoloji & 1 \\
Temel Eğitim & 1 \\
\hline
\end{tabular}


Tablo 9'a göre özel eğitimde teknoloji kullanımı ile ilgili tezleri yürüten araştırmacıların büyük çoğunluğu bilgisayar ve öğretim teknolojileri eğitimi $(f=11)$ ve özel eğitim $(f=8)$ alanlarında çalışmaktadır.

\section{Tartışma}

Bilim ve teknolojide meydana gelen gelişmeler, çağdaş kültürün en dikkat çekici niteliği olan maddi olanakları değiştirmesinin yanı sıra değer değişimine de neden olmaktadır. Böyle bir değişim ve dönüşüm ortamında eğitimin bilimsel ve teknolojik bir nitelik kazanması gerekliliği kaçınılmaz olmuştur (Alkan, 2005). Teknolojiden yararlanma sürecinde ise öğrenenlerin gereksinimleri farklılık göstermekte olup bu çerçevede teknolojinin kullanım şekilleri de çeşitlenmektedir. Teknolojinin gerek destekleyici gerek eğitici anlamda yeni dönüşümler yaşaması, özel eğitim alanı için büyük fursatlar sunmaktadır. Özel eğitim, doğası itibariyle gerek araç gerekse yöntem olarak teknoloji kullanımı ile genel eğitime birçok alanda önderlik yapan bir alan olup bu haliyle teknolojinin öncü dönüşüm alanlarından birisidir (Girgin, 2010).

$\mathrm{Bu}$ araştırmada özel eğitimde teknoloji kullanımı konusunda Türkiye'de yapılmış lisansüstü tezlerin incelenerek lisansüstü düzeydeki araştırmaların eğilimlerinin ortaya konulması ve gelecek araştırmalara yönelik fikir sunulması amaçlanmıştır. Bu amaç doğrultusunda özel eğitimde teknoloji kullanımı ile ilgili lisansüstü tezler yayın yılı, tez türü, yayınlandığı üniversite türü, yayınladığı üniversite, ele alınan özel eğitim kategorisi, elde edilen öğrenme çıktıları, kullanılan yöntem, kullanılan veri toplama araçları, yararlanılan teknoloji ve araştırmacı çalışma alanı açısından değerlendirilmiştir.

Özel eğitimde teknoloji kullanımı ile ilgili en fazla lisansüstü tez 2019 yılında yapılmıştır. Söz konusu tezlerden yüksek lisans tezleri özellikle son yıllarda sayıca artış gösterirken en fazla yüksek lisans tezinin yayınlandığı yıl 2016'dır. Benzer şekilde doktora tezleri de sayıca artarken en çok doktora tezinin yayınlandığı yıl 2019'dur. Bu durum özellikle son yıllarda özel eğitimde teknoloji kullanımının öne çıkan bir alan olduğunu göstermektedir. Özel eğitimde teknoloji kullanımı ile ilgili tezlerin büyük çoğunluğu devlet üniversitelerinde yapılmış olup en çok tez çalışması Anadolu Üniversitesi'nde yürütülmüştür. Lisansüstü tez çalışmalarının niceliğinin ilgili alandaki öğretim elemanı sayısına ve üniversite enstitülerinde bu konularda tez yapılmasına olanak sağlayacak anabilim dalı varlığına bağlı olduğu ifade edilmektedir (Çağlayan, 2018).

Özel gereksinimli bireylerin sınıflandırılmasında farklı yaklaşımlar söz konudur. Konu özel eğitim çerçevesinde değerlendirildiğinde temel olarak zihinsel yetersizlik, öğrenme güçlüğü, duygusal ve davranış bozukluğu, dikkat eksikliği ve hiperaktivite bozukluğu, otizm spektrum bozukluğu, dil ve konuşma bozukluğu, işitme yetersizliği, görme yetersizliği, ileri derecede ve çoklu yetersizlik, fiziksel yetersizlik, travmatik beyin yaralanması, üstün zekalılar ve üstün yetenekliler gibi kategoriler karşımıza çıkmaktadır (Turnbull, Turnbull, Wehmeyer ve Shogren, 2013). Özel eğitimde teknoloji kullanımına ilişkin tezler bu çerçevede değerlendirildiğinde tezlerin büyük çoğunluğu zihinsel yetersizlik kategorisinde yürütülmüştür. Söz konusu tezler öğrenme çıtıları bağlamında değerlendirildiğinde ise okuma, yazma, kavram öğretimi gibi akademik beceri odaklı oldukları görülmüştür. Alanyazın incelendiğinde özel eğitimde teknoloji temelli birçok araştırmada söz konusu bulguya benzer şekilde özel gereksinimli bireylere akademik becerilerin kazandırılmasının amaçlandığ 1 görülmektedir (Bellman, Burgstahler ve Hinke, 2015; İsmaili ve İbrahimi, 2016; TofelGrehl, Feldon ve Callahan, 2018; Wei, Yu, Shattuck ve Blackorby, 2017). Belli bir alandaki lisansüstü tez çalışmalarında konuların benzerliği o alanda yapılan ilk tez çalışmalarına esinlenme ile açıklanabilir (Coşkun, Dündar ve Parlak, 2014).

Alanyazın incelendiğinde bilimsel araştırmaların çeşitli ölçütler temel alınarak sınıflandırıldıkları görülmektedir (Büyüköztürk vd., 2013; Karasar, 2012). Özel eğitimde teknoloji kullanımı ile ilgili tez çalışmalarında en çok deneysel araştırmalar yürütülmüştür. Söz konusu araştırmalarda ise bir uygulamanın etkililiğinin her bir denekten standart koşullar altındaki yinelenen ölçümlerden elde edilen verilerle değerlendirildiği araştırmalar olarak ifade edilen tek denekli deneysel desenler (Tekin, 2000) öne çıkmaktadır. Tek denekli araştırma, tek bir bireyin bazen de az sayıda bireyden oluşan bir grubun bir süre yoğun bir şekilde incelenmesini ve üzerinde çalışılmasını içerir. Alanyazın incelendiğinde bu yöntem, diğer bireylerden (genelden) belirgin farklılıkları olan örneğin özel gereksinimli bireyler üzerinde çalışmak için uygun bir yöntem olarak ifade edilmektedir (Büyüköztürk vd., 2013). Buna karşın özel eğitimde teknoloji kullanımı ile ilgili tezlerde en az tercih edilen 
yöntemin ise eylem araştırması olduğu görülmüştür. Bu çerçevede alanyazın incelendiğinde yerel düzeylerde değişim ve gelişimin oluşturulabilmesinde en güçlü bilimsel yöntemlerden birisi olmakla birlikte eylem araştırması yönteminin, eğitimcilerin uygulama sonucunda çıkan değişimleri bir sonraki uygulamalara yansıtma sorumluluklarından kaynaklı uygulama zorluğu nedeniyle araştırmacılar tarafından daha az tercih edilen bir yöntem olduğu ifade edilmektedir (Özpınar ve Aydoğan Yenmez, 2015).

Özel eğitimde teknoloji kullanımı ile ilgili tezler veri toplama araçları çerçevesinde değerlendirildiğinde en çok kullanılan veri toplama araçları gözlem ve görüşmedir. Özel gereksinimli bireylerle yürütülen araştırmalarda ortaya çıkan bir davranışa ilişsin olarak ayrıntılı, kapsamlı ve derinlemesine veri elde etmek önemlidir. Bu çerçevede Yıldırım ve Şimşek (2011) tarafından bireylerin iç dünyasına girmek, onların bakış açılarını anlamak, oluşan davranışa ilişkin ayrıntılı bir resim elde etme amaçlı kullanılabilecek etkin veri toplama araçları arasında sayılan gözlem ve görüşme yöntemlerinin kullanıldığını söylemek mümkündür. Diğer yandan veri toplama araçlarının seçiminde etkili olan bir diğer faktörün ise katılımcı sayısının azlığı olduğu düşünülmektedir.

Özel eğitimde teknoloji kullanımı kaçınılmaz olup yardımcı teknolojiler, özel gereksinimli bireylerin eğitim faaliyetlerine tam ve yeterli biçimde katılabilmesi noktasında önemli olanaklar sunmaktadır. Yardımcı teknolojiler, engel durumuna yönelik uyarlanabilir ve iyileştirici teknolojileri de içeren şemsiye bir kavram olup (Chukwuemeka ve Samalia, 2020); özel gereksinimli bireyin çevresindeki bireylerle etkileşiminde yaşadığı sınıllılıkları azaltmak ya da ortadan kaldırarak, bireylerin yaşamını kolaylaştırmak için kullanılan her türlü aracı ifade etmektedir (Çoklar, Ergenekon ve Odabaşı, 2018). Teknoloji kullanımı, özel gereksinimli bireylerin sınıf tartışmalarına katılımlarını ve içerikle etkileşimlerini desteklerken bazı zor akademik görevleri yerine getirmelerine yardımcı olmaktadır (Alnahdi, 2014; Anderson ve Putman, 2020; Ciampa, 2017). Yardımcı teknolojiler özel gereksinimli bireyler için önemli olup sistemin bir bütün olarak tüm öğrenciler için kullanımında öğrenme için evrensel tasarım ilkelerinin önemine vurgu yapılmaktadır (Wehmeyer, 2006). Söz konusu evrensel tasarım ilkeleri adil kullanım, esnek kullanım, basit ve anlaş1ır kullanım, somut bilgi, kullanıcı hatalarına karşı toleranslı olma, düşük teknik ve fiziksel çaba, öğrenci topluluğu ve destek ile öğretim iklimi başlıklarında ele alınmaktadır (Elias, 2010). Özel eğitimde teknoloji kullanımı ile ilgili tezlerde mobil uygulamaların kullanım yoğunluğu dikkat çekmektedir. İçinde bulunduğumuz bilgi çağında bilgiye hızlı erişim önem kazanmaktadır. Bu noktada mobil teknolojiler öne çıkmaktadır. Mobil platformlar, öğrenen özelliklerine ve kullanıcı profillerine uygun uyarlanabilir ara yüzleri ile zamandan ve mekândan bağımsız, bireysel öğrenme sürecini destekleyen esnek öğrenme ortamlarının oluşturulabilmesini mümkün k1lmaktadır (Kagohara vd., 2013). Öğrenme sürecinde mobil teknolojilerin kullanımı ögrrencilerin derse olan ilgisini arttırarak eğlenirken öğrenmeyi olanaklı hale getirmektedir. Özel eğitime yönelik çoklu ortam uygulamalarında söz konusu mobil teknolojileri kullanan özel gereksinimli bireylerin öğrenmeye olan ilgilerinin ve dikkatlerinin arttığı ifade edilmektedir (FernáNdez-LóPez, RodríGuez-FóRtiz, RodríGuez-Almendros ve MartíNez-Segura, 2013). Sağladığı bu avantajlar nedeniyle incelenen araştırmalarda da mobil uygulamaların yaygın kullanımı söz konusudur. Teknolojik gelişmeler ışığında özel eğitim alanında son yıllarda yapay zekâ, arttırılmış gerçeklik gibi teknolojileri temel alan çalışmaların da yürütüldüğü görülmektedir (Lin vd., 2016). Arttırılmış gerçeklik uygulamaları sanal ortamların bir çeşidi olup özel gereksinimli bireylerin sanal dünya ile birleştirilmiş gerçek nesneleri görmelerini sağlayarak çevrelerindeki dünyanın bir parçası olarak etkili öğrenme sürecini desteklemektedir (Majumdar, 2016).

Araştırma kapsamında elde edilen bir diğer bulgu ise özel eğitimde teknoloji kullanımı ile ilgili tezleri yürüten araştırmacıların çalışma alanlarına ilişkindir. Bu çerçevede özel eğitim alanının yanı sıra teknoloji kullanımındaki rollerinin de etkisi ile bilgisayar ve öğretim teknolojileri eğitimi alanının öne çıktığını söylemek mümkündür. Disiplinlinler arası çalışmalar desteklenerek bu tür çalışmaların devamlılığ 1 sağlanmalıdır.

Özetle içinde bulunduğumuz bilgi çağında teknolojinin sunduğu olanaklardan etkin bir şekilde yararlanılması beklenmekte olup teknolojinin söz konusu gücünden özel eğitim alanında başta özel gereksinimli bireylere yeni davranış ve beceri kazandırılması sürecinde olmak üzere yaygın bir şekilde yararlanılmaktadır. Bu araştırma ile de Türkiye'de özel eğitim alanında teknoloji kullanımına ilişkin yürütülen lisansüstü tez çalışmalarındaki araştırma eğilimlerinin ortaya konulması amaçlanmıştır. Araştırma bulgularının, araştırmacılara yeni ve özgün konu belirlenmesi, teknolojinin bu alandaki gücüne ilişkin farkındalık geliştirilmesi ve alanyazına katkı sürecinde yararlı olacağı düşünülmektedir. 


\section{Kaynakça}

Alkan, C. (2005). Eğitim teknolojisi. Ankara: Anı Yayıncılık.

Alnahdi, G. (2014). Assistive technology in special education and the universal design for learning. The Turkish Online Journal of Educational Technology, 13(2), 18-23.

Anderson, S. E. \& Putman, R. S. (2020). Special education teachers' experience, confidence, beliefs, and knowledge about integrating technology. Journal of Special Education Technology, 35(1), 37-50.

Ayres, K. M. \& Langone, J. (2005). Intervention and instruction with video for students with autism: a review of the literature. Education and Training in Developmental Disabilities, 40(2), 183196.

Bellman, S., Burgstahler, S., \& Hinke, P. (2015). Academic coaching: outcomes from a pilot group of postsecondary STEM students with disabilities. Journal of Science Education for Students with Disabilities, 19(1), 39-49.

Blackhurst, A. E. (2005). Historical perspectives about technology applications for people with disabilities. D. Edyburn, K. Higgins \& R. Boone (Ed.), Handbook of special education technology research and practice içinde, (s. 1-27). WI: Knowledge by Design, Inc..

Büyüköztürk, Ş., Kılıç Çakmak, E., Akgün, Ö. E., Karadeniz, Ş., \& Demirel, F. (2013). Bilimsel araştırma yöntemleri. Ankara: Pegem Akademi.

Chukwuemeka, E. J. \& Samalia, D. (2020). Teachers' perception and factors limiting the use of hightech assistive technology in special education schools in North-West Nigeria. Contemporary Educational Technology, 11(1), 99-109.

Ciampa, K. (2017). Building bridges between technology and content literacy in special education: lessons learned from special educators' use of integrated technology and perceived benefits for students. Literacy Research and Instruction, 56, 85-113.

Coşkun, İ., Dündar, Ş., \& Parlak, C. (2014). Türkiye'de özel eğitim alanında yapılmış lisansüstü tezlerin çeşitli değişkenler açısından incelenmesi (2008-2013). Ege Eğitim Dergisi, 15(2), 375-396.

Çağlayan, N. (2018). Türkiye'de zihinsel engellilerde sanat eğitimi ile ilgili lisansüstü tezlerin incelenmesi. Anadolu Journal of Educational Sciences International, 8(2), 403-418.

Çoklar, A. N., Ergenekon, Y., \& Odabaş1 H. F. (2015). Özel eğitimde teknoloji. H. F. Odabaş1 (Ed.), Özel eğitim ve eğitim teknolojisi: kuramdan uygulamaya içinde, (s. 19-45). Ankara: Pegem Akademi.

Elias, T. (2010). Universal instructional design principles for Moodle. The International Review of Research in Open and Distributed Learning, 11(2), 110-124.

FernáNdez-LóPez, A., RodríGuez-FóRtiz, M. J., RodríGuez-Almendros, M. L., \& MartíNez-Segura, M. J. (2013). Mobile learning technology based on iOS devices to support with special education needs. Computers \& Education, 61, 77-90.

Girgin, C. (2010). Özel eğitimde dönüşümler. H. F. Odabaşı (Ed.), Bilgi ve iletişim teknolojileri ışı̆̆ında dönüşümler içinde, (s. 61-81). Ankara: Nobel Yayıncılık.

Hammond, D. L., Whatley, A. D., Ayres, K. M., \& Gast, D. L. (2010). Effectiveness of video modeling to teach iPod use to students with moderate intelectual disabilities. Education and Training in Autism and Developmental Disabilities, 45(4), 525.

İsmaili, J., \& İbrahimi, E. H. (2016). Mobile learning as alternative to assistive technology devices for special needs students. Education and Information Technologies, 22(3), 883-889.

Kagohara, D. M., van der Meer, L., Ramdoss, S., O’Reilly, M. F., Lancioni, G. E., Davis, T. N., Rispoli, M., Lang, R., Marschik, P. B., Sutherland, D., Green, V. A., \& Sigafoos, J. (2013). Using iPods in teaching programs for individuals with developmental disabilities: a systematic review. Research in Developmental Disabilities, 34(1), 147-156.

Karasar, N. (2012). Bilimsel araştırma yöntemi. Ankara: Nobel Yayıncılık.

Kuzgun, Y., \& Deryakulu, D. (2006). Bireysel farklılıklar ve eğitime yansımaları. Y. Kuzgun ve D. Deryakulu (Ed.), Eğitimde bireysel farklılıklar içinde, (2. Baskı), (s. 1-13). Ankara: Nobel Yayıncilik. 
Lin, C. Y., Chai, H. C., Wang, J. Y., Chen, C. J., Liu, Y. H., Chen, C. W., \& Huang, Y. M. (2016). Augmented reality in educational activities for children with disabilities. Displays, 42(1), 5154.

Majumdar, A. (2016). Utilizing Augmented Reality For Special Needs Learning. [Çevrimiçi]: http://elearningindustry.com/augmented-reality-for-special-needs-learning adresinden erişilmiştir.

McMillan, J. H. (2000). Educational research: fundamentals for the consumer. NY: Longman.

MEB. (2006). Özel Eğitim Hakkında Kanun Hükmünde Kararname. [Çevrimiçi]: http://orgm.meb.gov.tr/meb iys dosyalar/2012 10/10111011 ozel egitim kanun hukmunda _kararname.pdf adresinden erişilmiştir.

Mechling, L. C., \& Gustafson, M. R. (2008). Comparison of static picture and video prompting on the performance of cooking-related tasks by students with autism Journal of Special Education Technology, 23(3), 31-45.

Özpınar, İ., \& Aydoğan Yenmez, A. (2015). Eylem araştırması. M. Metin (Ed.), Kuramdan uygulamaya bilimsel araştırma yöntemleri içinde, (2. Baskı), (s. 441-467). Ankara: Pegem Akademi.

Ray, L. \& Atwill, K. (2004). The web and special education. Computers in the Schools, 21, 53-67.

Sherman, C. K., \& De La Paz, S. (2018). FIX: a strategic approach to writing and revision for students with learning disabilities. Teaching Exceptional Children, 48, 93-101.

Sula, A., \& Spaho, E. (2014). Using assistive technologies in autism care centers to support children develop communication and language skills. A case study: Albania. Academic Journal of Interdisciplinary Studies, 3(1), 203-212.

Tekin, E. (2000). Karşılaştırmalı tek-denekli araştırma modelleri. Ankara Üniversitesi Eğitim Bilimleri Fakültesi Özel Eğitim Dergisi, 2(4), 1-12.

Tofel-Grehl, C., Feldon, D. F., \& Callahan, C. M. (2018). Impacts of learning standards and testing on gifted learners in STEM scholls: a multilevel analytic induction. Roeper Review, 40(2), 130138.

Turnbull, A., Turnbull, R., Wehmeyer, M. L., \& Shogren, K. A. (2016). Exceptional lives. NJ: Pearson.

Wehmeyer, M. L. (2006). Universal design for learning, access to the general education curriculum and students with mild mental retardation. Exceptionality, 14, 225-235.

Wei, X., Yu, J. W., Shattuck, P., \& Blackorby, J. (2017). High school math and science preparation and postsecondary STEM participation for students with an autism spectrum disoerder. Focus on Autism and Other Developmental Disabilities, 32(2), 83-92.

Westling, D. L., \& Fox, L. (2009). Teaching students with severe disabilities. Merrill: Columbus.

WHO. (1980). International classification of impairments, disabilities, and handicaps: a manual of classification relating to the consequences of disease. Geneva: World Health Organization.

Yıldırım, A., \& Şimşek, H. (2011). Sosyal bilimlerde nitel araştırma yöntemleri. Ankara: Seçkin Yayıncilik.

Zisimopoulos, D., Sigafoos, J., \& Koutromanos, G. (2011). Using video prompting and constant time delay to teach an internet search basic skills to students with intellectual disabilities. Education and Training in Autism and Developmental Disabilities, 46(2), 238-250. 